\title{
Article \\ Morphological and Structural Characterization of Magnetron-Sputtered Aluminum and Aluminum-Boron Thin Films
}

\author{
Ulises Barajas-Valdes * and Oscar Marcelo Suárez (D)
}

check for

updates

Citation: Barajas-Valdes, U.; Suárez, O.M. Morphological and Structural Characterization of

Magnetron-Sputtered Aluminum and Aluminum-Boron Thin Films. Crystals 2021, 11, 492. https:// doi.org/10.3390/cryst11050492

Academic Editors: Xiaochun Li, Dariusz Bartkowski and Jakub Hajkowski

Received: 31 March 2021 Accepted: 23 April 2021 Published: 28 April 2021

Publisher's Note: MDPI stays neutral with regard to jurisdictional claims in published maps and institutional affiliations.

Copyright: (c) 2021 by the authors. Licensee MDPI, Basel, Switzerland. This article is an open access article distributed under the terms and conditions of the Creative Commons Attribution (CC BY) license (https:// creativecommons.org/licenses/by/ $4.0 /)$.
Nanotechnology Center, University of Puerto Rico-Mayagüez, PO Box 9000, Mayagüez, PR 00681, USA; oscarmarcelo.suarez@upr.edu

* Correspondence: ulises.barajas@upr.edu

Abstract: In microelectronic mechanical systems applications, sputtered aluminum thin films may have large roughness, which promotes the optical degradation and electromigration. This challenge motivated the present research, where magnetron sputtering equipped by radio frequency allowed for preparing aluminum and aluminum-boron thin films. This study evaluated the effect of the sputtering power and the substrate type (silicon wafer and glass slides) on the deposited films. The film's morphology and structure were characterized via an atomic force microscope and X-ray diffraction. Pure aluminum films' topographic findings revealed a $25.23 \mathrm{~nm}$ average roughness with larger grain size and hillock formation. Conversely, the aluminum-boron films possessed a $3.41 \mathrm{~nm}$ average roughness, with smaller grains and hillocks suppression when higher sputtering power was used. The pure aluminum films' structural analysis uncovered a material with low crystallinity, with (111) and (200) planes diffracting X-rays. On the other hand, aluminum-boron films displayed better crystallinity and a preferential (111) texture. Further characterization demonstrated how the sputtering power, the substrate material, and the studied targets affected the films' morphological and structural. The improvements in morphological and structural aspects that were observed in the films that were obtained via the aluminum-boron target sputtering make this methodology an appealing alternative for metal films manufacturing.

Keywords: composite material; thin film; roughness; grain size; hillock; texture

\section{Introduction}

High surface roughness has been a detrimental characteristic of aluminum thin films that formed by physical vapor deposition (PVD). Said roughness is related to the film thickness and sputtering power, factors that affect the grain size and even lead to hillocks development. [1-4]. These detrimental occurrences promote optical reflectance degradation [5-7] and electromigration phenomenon (mass transport), bringing down operation effectiveness and useful lifetime of micro-electronic-mechanical systems (MEMs), i.e., the intended application of these materials [8-10]. Furthermore, the structural studies of metallic films through X-ray diffraction have found that the deposited material can have amorphization or low crystallinity $[7,11,12]$. Lest the occurrence of such defects in aluminum films, researchers have looked for ways to counteract them. For instance, prior studies in thin films that are made of aluminum composite materials [11,13] or aluminum alloys $[7,12,14]$ showed less surface roughness and improved films structure (crystallinity). These improvements resulted from the constituents of the deposition material that helped decrease the grain size and hillock formation. Another research on aluminum films sputtered using a nitrogen-argon mixture revealed that this atmosphere improved the material surface, leading to a flatter topography (i.e., fewer hillocks) [15]. Argon prevented potential reactiveness if nitrogen had been employed. In this later case, although a smoother film would have resulted, some incompletely nitride material would have formed. The works 
above indicate that additional studies in better understanding the key tenets of thin films topography are required when dealing with aluminum thin films made by magnetron sputtering. The present research expands the work by Ramos and Suárez, who manufactured thin films from a monolithic composite target (Al-Si-B) [11], by focusing on the deposition of an aluminum matrix composite (Al-4\%wt. B) and pure aluminum. In addition to the nature of the target material, the effect of specific sputtering parameters and different substrate types (glass slides and silicon wafer) were examined. In summary, the main aim of the present study has been to interpret the influence of sputtering conditions on the mechanisms of thin film formation through the study of the surface morphology (via atomic force microscopy) and its structure (via X-ray diffraction).

\section{Experimental and Characterization}

\subsection{Materials}

The target materials that were used to fabricate the films were: (a) aluminum $(99.999 \%$ purity) and (b) a composite made of $\mathrm{Al} 4 \% w t$. B (Al-4B). The latter aluminum matrix composite is reinforced with 3 to $10 \mu \mathrm{m}$ diboride particles $\left(\mathrm{AlB}_{2}\right)$ [16]. The composite was prepared using a master one (Al 5\%wt. B) and pure aluminum that we centrifugally cast applying a methodology that was originally developed by Adelakin and Suárez [17]. To this purpose, we melted the material at $700^{\circ} \mathrm{C}$ in a graphite crucible and poured it into a preheated $\left(400^{\circ} \mathrm{C}\right)$ transfer scoop and into the mold where the melt underwent a 350-rpm rotation speed for $10 \mathrm{~min}$. As a result, the centrifuged target had a much lower porosity than the specimens prepared through conventional gravity casting [18].

\subsection{Thin Films}

A magnetron sputtering unit (ATC Orion, AJA International, North Scituate, MA, USA) allowed for depositing the films using the radio frequency (RF) mode and the following parameters: (a) argon mass flow of $0.0128 \mathrm{~L} / \mathrm{min}$. [11], (b) vacuum chamber pressure at $0.267 \mathrm{~Pa}$ [11] backfilled with $\mathrm{Ar}$, (c) a $10 \mathrm{~cm}$ distance between target and substrate, and (d) a $40 \mathrm{rpm}$ substrate rotation. The studied sputtering powers were 100, 130, 160, and $200 \mathrm{~W}$. As mentioned, we used two deposition substrates: a glass slide (GS) and a single crystal silicon wafer (SW) with its (001) plane exposed to the film (i.e., serving as interface). Both of the substrates were cleaned thoroughly with methanol, isopropanol, and acetone.

The target films thickness was set to reach $500 \mathrm{~nm}$. The selected thickness was based on the results from a prior investigation by Barajas and Suarez. In that work, the authors demonstrated that, with that thickness, the films' mechanical properties of the films analyzed were not affected by the substrate nature. The technique used was the continuous stiffness measurement [18]. Therefore, these effects will be evaluated regarding the surface morphology of films material. For the said sputtering conditions and for each power, the deposition rates that were attained in the Al material were of $0.06,0.08,0.09$, and $0.12 \mathrm{~nm} / \mathrm{s}$, while, for the Al-4B material, were of $0.05,0.07,0.08$, and $0.10 \mathrm{~nm} / \mathrm{s}$, respectively. The sputtering rates were previously computed based on the deposition times, as described in our prior research [19]. A KLA Tencor (Milpitas, CA, USA) profilometer allowed measuring the resulting film thickness.

\subsection{Characterization}

The characterization techniques used revealed the films surface morphology as well as their crystal structure. Atomic force microscopy (AFM) and x-ray diffraction (XRD) allowed for determining these properties of the sputtered material.

\subsubsection{Surface Morphology}

The films surface morphology analysis encompassed surface roughness, grain size, and hillock formation. In addition, the substrate effect was assessed during the film surface roughness measurements. The samples topography data were acquired by a Veeco, Model di CPII AP0100 atomic force microscope (AFM, Veeco, Plainview, NY, USA), operating in no- 
contact mode. The scanned film surface areas were $625,100,25,9$, and $2.25 \mu \mathrm{m}^{2}$. Afterward, the AFM images were evaluated using the SPIP ${ }^{\mathrm{TM}}$ software from Image Metrology.

\subsubsection{Crystal Structure}

The crystal structure of the films was evaluated through the diffraction patterns obtained in a Rigaku ULTIMA III diffractometer (Applied Rigaku Technologies, Inc., Austin, TX, USA). This was furbished with a $\mathrm{Cu}$ target $(\mathrm{Cu} \mathrm{K} \alpha$ radiation $\lambda=0.15418 \mathrm{~nm})$ and it was operated at $40 \mathrm{kV}$ and $44 \mathrm{~mA}$ for a $30^{\circ}$ to $70^{\circ} 2 \theta$ range.

\section{Results and Discussion}

\subsection{Surface Morphology}

As mentioned, an AFM allowed for studying the surface morphology of the films. Thus, this instrument allowed quantifying the root mean square (RMS) roughness, grain size, and hillock formation of the sputtered films.

\subsubsection{RMS Assessment}

Table 1 presents the results of the average RMS. The computed RMS on both substrates revealed smaller roughness on the Al-4B-deposited films compared to the aluminum films. The measured RMS were $3.05 \mathrm{~nm}$ on the silicon wafer and $3.41 \mathrm{~nm}$ on the glass slide (Table 1). Moreover, aluminum produced an RMS of 25.23 and $23.43 \mathrm{~nm}$, on the respective substrates (Table 1). In this table, the error bar value demonstrates the dispersion of the measured roughness of the films' material having $500 \mathrm{~nm}$ thickness.

Table 1. RMS roughness summary of Al-4B films and pure aluminum films deposited on silicon wafer and glass slide, for each scan area and sputtering power.

\begin{tabular}{|c|c|c|c|c|c|c|c|c|c|c|}
\hline Substrate & \multicolumn{5}{|c|}{ Silicon Wafer } & \multicolumn{5}{|c|}{ Glass Slide } \\
\hline Material & \multicolumn{10}{|c|}{ Al-4B films } \\
\hline $\begin{array}{l}\text { Sputtering } \\
\text { Power }\end{array}$ & \multicolumn{5}{|c|}{ Scan Area $\left(\mu \mathrm{m}^{2}\right)$} & \multicolumn{5}{|c|}{ Scan Area $\left(\mu \mathrm{m}^{2}\right)$} \\
\hline (watts) & 2.25 & 9 & 25 & 100 & 625 & 2.25 & 9 & 25 & 100 & 625 \\
\hline 100 & 3.11 & 3.21 & 3.63 & 3.48 & 4.31 & 3.11 & 2.63 & 2.57 & 2.75 & 4.45 \\
\hline 130 & 2.14 & 2.17 & 2.51 & 2.48 & 4.12 & 1.75 & 2.11 & 2.26 & 2.74 & 5.03 \\
\hline 160 & 2.82 & 2.96 & 3.16 & 3.09 & 3.36 & 2.92 & 3.09 & 3.29 & 3.51 & 6.01 \\
\hline 200 & 2.91 & 2.74 & 2.66 & 2.93 & 3.14 & 3.20 & 3.62 & 3.95 & 3.96 & 5.28 \\
\hline Error Bar & \multicolumn{5}{|c|}{0.09} & \multicolumn{5}{|c|}{0.17} \\
\hline $\begin{array}{c}\text { RMS } \\
\text { Average }\end{array}$ & \multicolumn{5}{|c|}{3.05} & \multicolumn{5}{|c|}{3.41} \\
\hline Material & \multicolumn{10}{|c|}{ Aluminum Films } \\
\hline $\begin{array}{l}\text { Sputtering } \\
\text { Power }\end{array}$ & \multicolumn{5}{|c|}{ Scan Area $\left(\mu \mathrm{m}^{2}\right)$} & \multicolumn{5}{|c|}{ Scan Area $\left(\mu \mathrm{m}^{2}\right)$} \\
\hline (watts) & 2.25 & 9 & 25 & 100 & 625 & 2.25 & 9 & 25 & 100 & 625 \\
\hline 100 & 20.35 & 21.20 & 46.13 & 19.27 & 27.86 & 14.52 & 17.34 & 23.12 & 33.53 & 29.36 \\
\hline 130 & 15.94 & 14.75 & 25.66 & 33.71 & 33.39 & 17.43 & 15.94 & 17.99 & 31.90 & 35.91 \\
\hline 160 & 9.39 & 13.93 & 32.35 & 29.60 & 28.48 & 11.90 & 12.85 & 16.24 & 26.32 & 31.99 \\
\hline 200 & 17.68 & 27.29 & 31.57 & 30.47 & 25.49 & 18.50 & 23.93 & 29.09 & 31.45 & 29.93 \\
\hline Error Bar & \multicolumn{5}{|c|}{1.34} & \multicolumn{5}{|c|}{1.19} \\
\hline $\begin{array}{c}\text { RMS } \\
\text { Average }\end{array}$ & \multicolumn{5}{|c|}{25.23} & \multicolumn{5}{|c|}{23.46} \\
\hline
\end{tabular}

One can better visualize the said dispersion in the three-dimensional bar charts in Figures 1 and 2, presenting the roughness as a function of the scan area and the sputtering power. In aluminum films, the dispersion was significant for each analysis point on both substrates (Figure 1), unlike the Al-4B films (Figure 2). 

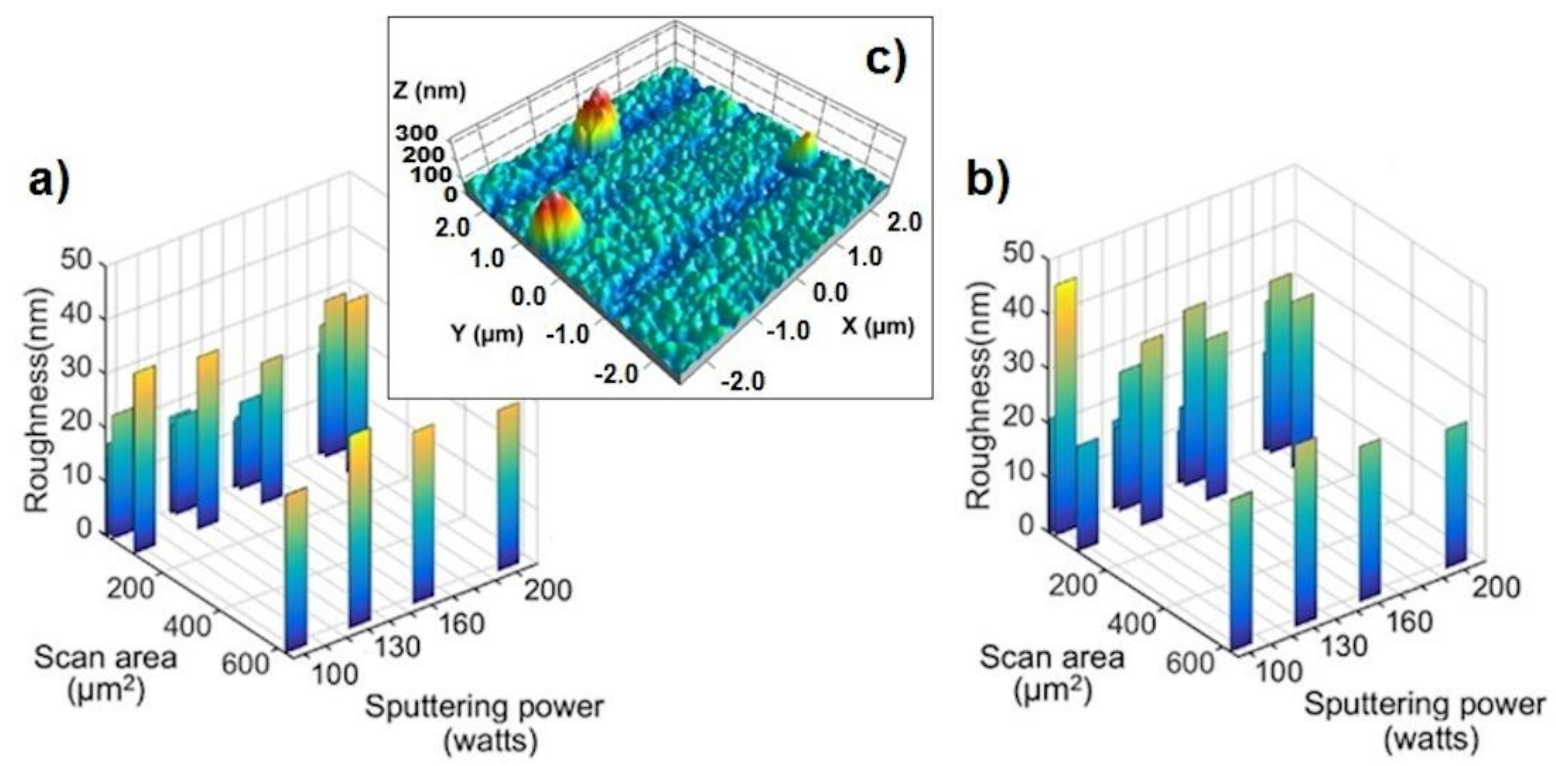

Figure 1. Bar charts of RMS in the aluminum films deposited on (a) glass, (b) silicon wafer, and (c) 3D AFM images of deposited at $200 \mathrm{~W}$ onto a silicon wafer for the scan areas of $25 \mu \mathrm{m}^{2}$.
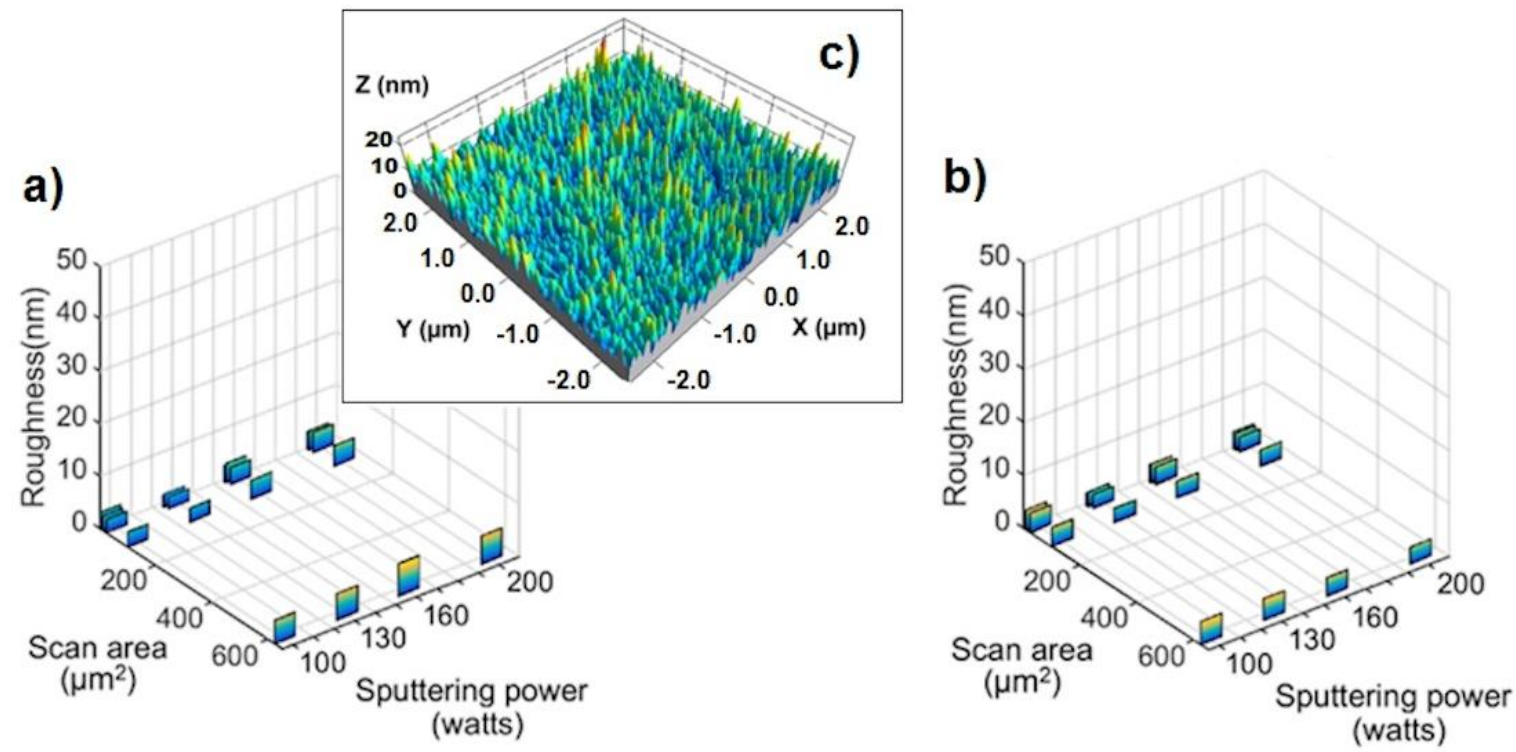

Figure 2. Bar charts of RMS in the Al-4B films deposited on (a) glass, (b) silicon wafer, and (c) 3D AFM images of deposited at $200 \mathrm{~W}$ onto a silicon wafer for the scan areas of $25 \mu \mathrm{m}^{2}$.

The literature has reported that this scattering is associated with the grain texture, a factor prompting hillocks formation that heightens the roughness of the film's surface [3,12,20-24]. These hillocks are formed by compressive stresses that are generated upon sputtering when soft metallic materials are used (like pure aluminum). The stresses are the result of the thermal expansion differences between deposited material and substrate [25]. Furthermore, hillocks represent a mechanism of stress relaxation where deposited atoms diffuse into the grain boundaries [25-27]. Indeed, the 3D-AFM image shown in Figure 1c, i.e., the sample deposited on the silicon wafer at $200 \mathrm{~W}$ presents an instance of the hillock formation in this film material, where the protuberances on the aluminum film surface are apparent. In conclusion, we have corroborated that the dispersion of roughness in aluminum films is related to the trend that is observed in the hillocks formation.

Conversely, the Al-4B film image (Figure 2c) did not display such protrusions, i.e., the resulting surface was more uniform. This figure, like its aluminum counterpart (Figure 1c), 
was obtained from a sample that was deposited on the silicon wafer at $200 \mathrm{~W}$. The composite material (Al-4B) film bore a more considerable resistance to hillock formation, a fact that is supported by the literature, which attributes this to impurities (alloys) or other effects (e.g., different atmospheres). $[5,12,15,22,28]$. In our case, the target material contained $\mathrm{AlB}_{2}$ particles, as indicated in a prior section.

\subsubsection{Substrate Effects}

The overall roughness results for the pure aluminum and Al-4B films did not unveil an apparent substrate-related effect. The aluminum and the Al-4B films deposited on the silicon wafer and the glass slide both showed similar roughness characteristics, according to the surface scanning outcome of the films using the AFM (Figures 1 and 2). We believe that the thickness of the films, i.e., $500 \mathrm{~nm}$, masked any effect of the substrate on the material's surface roughness.

When considering this trend, we believe that the films thickness, i.e., $500 \mathrm{~nm}$, masks any effect of the substrate on the surface roughness of each material. Bearing this in mind, we decided to explore and measure the roughness in films deposited at $200 \mathrm{~W}$ with thicknesses of 500 and $100 \mathrm{~nm}$. This would allow validating prior substrate effect results related to thickness film. These films were analyzed with AFM scan areas of $0.25,1.0$, $2.25,9.0$, and $25 \mu^{2}$. The outcome, as shown in Table 2, demonstrates that the roughness values of $\mathrm{Al}-4 \mathrm{~B}$ films measured on the silicon wafer and glass slide tend to overlap for each scanning area corresponding to the 500 and $100 \mathrm{~nm}$ thicknesses. Because the average RMS ranged from 2.05 to $3.02 \mathrm{~nm}$ (Table 2), we believe that this material roughness was not considerably affected by the film thickness and substrate nature.

Table 2. RMS roughness for Al-4B and aluminum films deposited at $200 \mathrm{~W}$ onto the silicon wafer and glass slide substrates, with thicknesses of 100 and $500 \mathrm{~nm}$.

\begin{tabular}{|c|c|c|c|c|c|c|c|c|}
\hline \multirow{2}{*}{$\begin{array}{c}\text { Film } \\
\text { Substrate }\end{array}$} & \multicolumn{4}{|c|}{ A1-4B } & \multicolumn{4}{|c|}{ Aluminum } \\
\hline & \multicolumn{2}{|c|}{ Silicon Wafer } & \multicolumn{2}{|c|}{ Glass Slide } & \multicolumn{2}{|c|}{ Silicon Wafer } & \multicolumn{2}{|c|}{ Glass Slide } \\
\hline \multirow{3}{*}{ Scan Area $\left(\mu \mathrm{m}^{2}\right)$} & \multicolumn{2}{|c|}{ Thickness (nm) } & \multicolumn{2}{|c|}{ Thickness (nm) } & \multicolumn{2}{|c|}{ Thickness (nm) } & \multicolumn{2}{|c|}{ Thickness (nm) } \\
\hline & 100 & 500 & 100 & 500 & 100 & 500 & 100 & 500 \\
\hline & \multicolumn{4}{|c|}{ RMS roughness } & \multicolumn{4}{|c|}{ RMS Roughness } \\
\hline 0.25 & 1.67 & 2.27 & 1.89 & 2.47 & 6.13 & 12.51 & 9.20 & 13.26 \\
\hline 1.00 & 1.80 & 2.19 & 2.15 & 2.53 & 8.12 & 23.60 & 8.98 & 18.94 \\
\hline 2.25 & 1.92 & 2.27 & 2.31 & 3.07 & 8.33 & 14.85 & 8.96 & 12.83 \\
\hline 9.00 & 2.21 & 2.48 & 2.67 & 3.34 & 8.13 & 18.81 & 8.98 & 17.47 \\
\hline 25.00 & 2.64 & 2.93 & 3.30 & 3.68 & 12.55 & 28.02 & 9.00 & 16.56 \\
\hline Average RMS & 2.05 & 2.43 & 2.47 & 3.02 & 8.65 & 19.56 & 9.02 & 15.81 \\
\hline
\end{tabular}

On the other hand, the aluminum film roughness did evince some variation, specifically on the $500 \mathrm{~nm}$ thick samples, where the average roughness reached 19.56 and $15.81 \mathrm{~nm}$ on SW and GS, respectively (Table 2). These were larger than the RMS values, i.e., 8.6 and $9.02 \mathrm{~nm}$, as measured in the $100 \mathrm{~nm}$ thick films (Table 2). Thus, one can conclude that the film thickness did affect the roughness. Such a roughness gain in thicker films is attributed to the grain size growth by grains coalescence as well as hillock formation $[2,4,5,15,29]$. Subsequently, the roughness values in the $100 \mathrm{~nm}$ samples (Table 2) suggest that the material surface was not affected by the amorphous (GS) or crystalline (SW) nature of the substrate. This morphological behavior could have resulted from low crystallization upon the early stages of the film formation, as reported by Khachatryan et al. [1]. These authors detected that, for the first $10 \mathrm{~nm}$, aluminum films that were deposited over steel substrates, did not present grain growth due to the absence of crystallization. This factor led to a smoother surface (lower roughness). Subsequently, the roughness became relevant when the film 
thickness exceeded $50 \mathrm{~nm}$, as the grain growth process began. From here on, the granular coalescence is promoted forming islands, which raised the aluminum film roughness.

\subsubsection{Average Grain Size}

The average grain size (alternatively called grain diameter) of the films was measured on AFM images acquired on a $2.25 \mu \mathrm{m}^{2}$ scan area. The accompanying Appendix A describes the procedure (i.e., grain size measurement). Table 3 shows the mean grain diameters using each grain area (as computed by the SPIP ${ }^{\mathrm{TM}}$ software). The results demonstrate how the aluminum films presented a larger grain size. For instance, the average grain size was $152.14 \mathrm{~nm}$ in the sample deposited at $200 \mathrm{~W}$. Additionally, the values of the coefficient of variation $\mathrm{C} v$ revealed the heterogeneity (grain size variability). Conversely, the Al-4B films comprised smaller and more uniform grains, according to their $C v$. Higher deposition power reduced the average grain size, e.g., at $200 \mathrm{~W}$, the mean grain size only becomes $79.20 \mathrm{~nm}$ (Table 3).

Table 3. Average grain size results for $500 \mathrm{~nm}$ thick aluminum and Al-4B films, with thickness sputtered at 100, 130, 160, and $200 \mathrm{~W}$.

\begin{tabular}{ccccccc}
\hline Material & Al & \multicolumn{3}{c}{ Al-4B } \\
\hline $\begin{array}{c}\text { Sputtering Power } \\
\text { (Watts) }\end{array}$ & $\begin{array}{c}\text { Diameter } \\
\text { (nm) }\end{array}$ & STD & $\mathbf{C v}$ & $\begin{array}{c}\text { Diameter } \\
(\mathbf{n m})\end{array}$ & STD & $\mathbf{C v}$ \\
\hline 100 & 117.24 & 57.40 & 0.49 & 97.12 & 31.37 & 0.32 \\
130 & 118.98 & 46.87 & 0.39 & 90.21 & 24.80 & 0.27 \\
160 & 150.34 & 66.26 & 0.44 & 75.66 & 29.05 & 0.38 \\
200 & 152.14 & 86.59 & 0.57 & 79.20 & 20.69 & 0.26 \\
\hline
\end{tabular}

Next, a box and whisker diagram allowed for observing said grain size dispersion concerning the median and the average grain size. The $\mathrm{Q}_{1}, \mathrm{Q}_{2}$, and $\mathrm{Q}_{3}$ quartiles represent $25 \%, 50 \%$, and $75 \%$ of the ordered data, respectively. The $\mathrm{Xmin}$ is $\mathrm{Q} 1-1.5 \cdot\left(\mathrm{Q}_{3}-\mathrm{Q}_{1}\right)$ and $\mathrm{Xmax}, \mathrm{Q}_{3}+1.5 \cdot\left(\mathrm{Q}_{3}-\mathrm{Q} 1\right)$. Additionally, this plot permitted to identify outliers (x) lying outside the limits Xmin and Xmax. Hence, this statistical tool revealed how the data are not only dispersed around the median $\left(\mathrm{Q}_{2}\right)$ but also how said data are distributed around the lower quartile $\left(Q_{1}\right)$, upper quartile $\left(Q_{3}\right)$, and the extremes $(X \min , X \max )$ or whiskers, as shown in Figure 3a [30].

a)

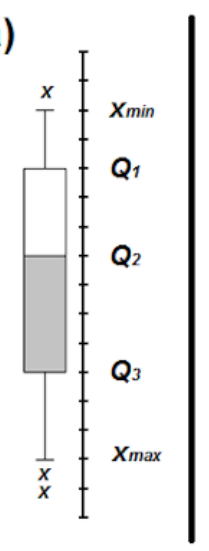

b)

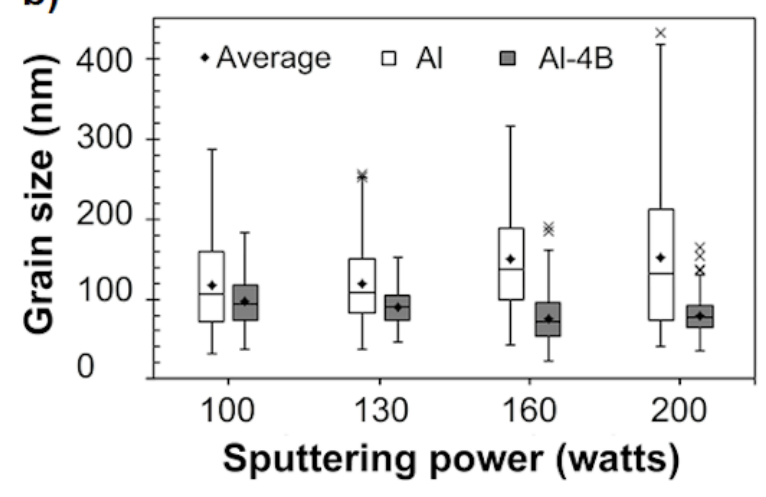

Figure 3. (a) Box and whisker plot sketch and (b) grain size box plots computed for the aluminum and $\mathrm{Al}-4 \mathrm{~B}$ films as a function of the sputtering power.

For the aluminum samples, the box size shown in Figure $3 \mathrm{~b}$ was more prominent than for the Al-4B specimens, and even more for specimens sputtered with larger power. One can also observe that, in those aluminum samples, the lengths of the upper boxes and whiskers extend more toward the top of the diagram from the median value $\left(\mathrm{Q}_{2}\right)$. 
Graphically, this points that the grain size of these specimens (made of pure aluminum) does not evince symmetry with respect to the median value, but tends to be more disperse nigh the larger grains. In the $\mathrm{Al}-4 \mathrm{~B}$ samples, the lengths of the upper and lower boxes in the diagram were smaller and about the same size. The median $\left(\mathrm{Q}_{2}\right)$ lies near the box plot center, which is a feature of the data symmetry or homogeneity, i.e., the grain size. One should also note that, in these films, the median and average values are similar, which supports the notion of data homogeneity around the mean grain size, unlike pure aluminum films (Figure $4 \mathrm{~b}$ ). Therefore, the diagram boxes enabled us to more effectively confirm the films uniform grain size further evinced by the coefficients of variations $(\mathrm{Cv})$ in Table 3.
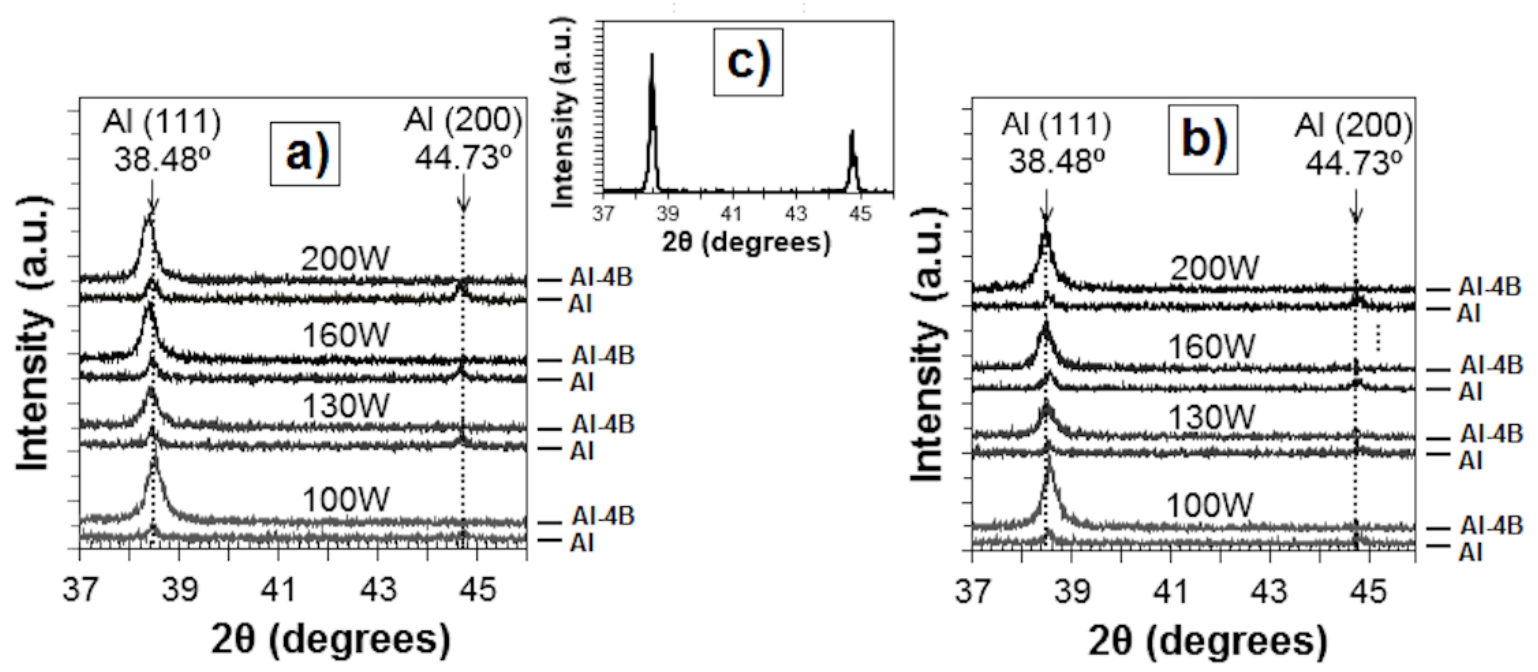

Figure 4. XRD patterns for aluminum films and Al-4B films deposited on (a) glass slide and (b) Scheme 100, 130, 160, and $200 \mathrm{~W}$ ), and (c) X-ray diffraction pattern obtained from pure aluminum powder sample.

As mentioned, the aluminum films roughness relates to the grain size and hillocks. Upon sputtering, soft aluminum becomes affected by diffusion processes between the grains due to stress relaxation, as the grains coalesce when the thickness rises. This occurrence then leads to a larger grain size in the film material $[2,4,5,29]$. The sputtering power also contributes to the film's grain size and hillock formation, as high power levels yield higher sputtered atom density with a large energy reaching the substrate and prompting a steep nucleation density $[2,20,23,31,32]$.

On the other hand, the Al-4B films presented a lower RMS roughness, as well as shorter hillocks and a smaller grain size. One must recall that these Al-4B films were made of a composite (Al-4wt. \% B) deposition target, i.e., an aluminum matrix that is reinforced with AlB2 microparticles. We believe that pieces of the sputtered particles that are embedded in the $\mathrm{Al}$ matrix induced those changes on the surface morphology of the film. This is consistent with what has been found in a previous work where $\mathrm{AlB}_{2}$ particles in the target were found to be "chiseled out" by the high-energy plasma [33]. Let us also remember that film growth rate hinges not only on the target material's transfer rate onto the substrate (affected by vacuum, pressure, and sputtering power), but also on surface events, such as nucleation, adsorption, reaction, and desorption [27,34-36]. Ramos and Suárez reported similar findings in a study of metallic films that were fabricated with composite targets of Al-B-Si deposited on silicon wafer via a similar magnetron sputtering unit [11]. Those composite targets contained $\mathrm{AlB}_{2}$ and $\mathrm{AlB}_{12}$ particles that were embedded in an aluminum-silicon matrix; upon pulverization, they rendered a smooth film surface when compared to the aluminum films surface that was deposited with the same deposition parameters. However, their characterization techniques were not sufficient to detect $\mathrm{AlB}_{2}$ or $\mathrm{AlB}_{12}$ particles within the thin films. It is possible that the size of the sputtered particles was below the detection levels of their instrumentation. 
Other works on metallic films that were manufactured with aluminum alloys reported similar results concerning surface morphology. Kylner and Mattsson studied aluminum and Al-Cu films deposited on silicon wafer via a co-evaporation (two targets) technique [6]. They found that the Al-Cu film grain size was 50\% smaller than pure aluminum film grains. The presence of copper solute atoms in the co-evaporated Al-Cu films enabled the formation of small grains. Similarly, another study conducted by Drassilia et al. focused on a composite target to manufacture $\mathrm{Al}-\mathrm{Cu}$ films by sputtering; the authors observed the formation of $\alpha \mathrm{Al}$ solution and intermetallic compounds $\left(\mathrm{Cu}_{3} \mathrm{Al}, \theta\left(\mathrm{Al}_{2} \mathrm{Cu}\right)\right)$ in the films via XRD [14]. The authors revealed that these combined factors promoted the grain refinement in the sputtered films. In another research, Barron introduced alloying elements to the Al-Cu alloy films, namely titanium and chromium [22]. Using AFM images, the authors observed smaller grain sizes and hillock suppression in the films containing $\mathrm{Al}-\mathrm{Cu}-\mathrm{Ti}$ and $\mathrm{Al}-\mathrm{Cu}-\mathrm{Cr}$ as compared to films made of pure aluminum and $\mathrm{Al}-\mathrm{Cu}$. The $\mathrm{Cu}, \mathrm{Ti}$, or $\mathrm{Cr}$ presence favored smoother films.

In general, those previous works demonstrated how alloying atoms or impurities present in the target material upon sputtering deposition could affect the surface morphology of the films. These films show grain refinement and smooth surfaces, as reflected by low roughness measurements. Therefore, the low roughness and grain size of our samples that were prepared with the Al-4B target could be associated with the very small AlB2 particles or even free boron atoms that render smoother film surfaces.

\subsection{Structural Evaluation}

X-ray diffraction allowed insight into the films' structure of the samples deposited on the glass slide and silicon wafer substrates at different sputtering power. Figure 4 presents the resulting diffractograms.

The aluminum films diffraction patterns reveal two peaks with a weak intensity over both substrates (Figure 4), corresponding to the reflections of the (111) and (200) crystallographic planes, according to the JCPDS 04-0787 powder diffraction standards (Figure 4). Such a low intensity could bespeak the films' low crystallinity. Deposited aluminum may bear some amorphization due to high crystal defect density being rendered upon film deposition [12,33,37]. Conversely, the Al-4B films patterns exhibited one large (111) peak, according to Figure 4 . The broad peak points at the nanoscaled grain structure and its sole occurrence (that is, no other peak is apparent) could be indicative of preferential orientation during growth (texture) $[6,26,38,39]$. It is apparent, then, that the Al-4B target material, upon RF sputtering, enhanced the Al-4B film crystallinity. The high energy of the sputtered atoms when RF is used $[28,40]$ somehow improved such crystallinity, as revealed by the diffraction peak intensities $[21,22,32,33,40]$.

As mentioned, an AFM allowed for studying the surface morphology of the films. Thus, this instrument allowed quantifying the root mean square (RMS) roughness, grain size, and hillock formation of the sputtered films.

We computed the interplanar distance $(d)$ for the cubic structure using Bragg's law (Equation (1)) for each sputtering power to further scrutinize these XRD results mainly related the (111) plane of Figure 4.

$$
\lambda=2 d_{h k l} \sin \theta_{h k l}
$$

where $\lambda$ is the wavelength of the $X$-ray, i.e., $\operatorname{CuK} \alpha(\lambda=0.15418 \mathrm{~nm}) ; d_{h k l}$ is the interplanar distance; and, $\theta$ is half the angle between the diffracted and non-diffracted beam. The $2 \theta$ value position of the (111) peak was computed using the centroid method [41]. Besides, for a cubic crystal, the lattice parameter a can be calculated according to Equation (2), where $h$, $k$, and $l$ are the Miller indices of the plane separated by $d_{h k l}$.

$$
d_{h k l}=\mathrm{a} /\left(h^{2}+k^{2}+l^{2}\right)
$$


Table 4 summarizes the results of the (111) peak analysis. These results were compared to an aluminum powder sample (Figure 4c) that was analyzed with the same Rigaku ULTIMA III diffractometer, using CuK $\alpha$ radiation. The pure aluminum sample represented a reference value of the lattice parameter $a$, when only the (111) plane position was considered. We acknowledge that a value, provided by the literature, uses more crystallographic planes for its calculation (according to the JCPDS 04-0787 standard). This pure aluminum powder pattern displays the (111) and (200) peaks that match the diffraction standard. For this sample, the $2 \theta$ position of the (111) peak that was computed by the centroid method was $38.48^{\circ}$, and the corresponding values of the interplanar distance and the lattice parameter were $d=0.2339$ and $a=0.4052 \mathrm{~nm}$, using Equations (1) and (2).

Table 4. Lattice parameters computed for the films that were deposited on the silicon wafer and glass slide substrates.

\begin{tabular}{|c|c|c|c|c|c|c|}
\hline \multirow{2}{*}{$\begin{array}{c}\text { Target Material } \\
\text { Substrate }\end{array}$} & \multicolumn{3}{|c|}{ Al-4B } & \multicolumn{3}{|c|}{ Al } \\
\hline & \multicolumn{6}{|c|}{ Silicon Wafer } \\
\hline $\begin{array}{l}\text { Sputtering Power } \\
\text { (watts) }\end{array}$ & $\begin{array}{c}2 \theta \\
\text { (degrees) }\end{array}$ & $\begin{array}{c}d \\
(\mathrm{~nm})\end{array}$ & $\begin{array}{c}a \\
(\mathrm{~nm})\end{array}$ & $\begin{array}{c}2 \theta \\
\text { (degrees) }\end{array}$ & $\begin{array}{c}d \\
(\mathrm{~nm})\end{array}$ & $\begin{array}{c}a \\
(\mathrm{~nm})\end{array}$ \\
\hline 100 & 38.581 & 0.2334 & 0.4042 & 38.562 & 0.2335 & 0.4044 \\
\hline 130 & 38.531 & 0.2343 & 0.4047 & 38.557 & 0.2341 & 0.4044 \\
\hline 160 & 38.492 & 0.2344 & 0.4051 & 38.549 & 0.2340 & 0.4045 \\
\hline 200 & 38.489 & 0.2345 & 0.4051 & 38.559 & 0.2341 & 0.4044 \\
\hline Substrate & \multicolumn{6}{|c|}{ Glass Slide } \\
\hline $\begin{array}{l}\text { Sputtering Power } \\
\text { (watts) }\end{array}$ & $\begin{array}{c}2 \theta \\
\text { (degrees) }\end{array}$ & $\begin{array}{c}d \\
(\mathrm{~nm})\end{array}$ & $\begin{array}{c}a \\
(\mathrm{~nm})\end{array}$ & $\begin{array}{c}2 \theta \\
\text { (degrees) }\end{array}$ & $\begin{array}{c}d \\
(\mathrm{~nm})\end{array}$ & $\begin{array}{c}a \\
(\mathrm{~nm})\end{array}$ \\
\hline 100 & 38.507 & 0.2338 & 0.4049 & 38.461 & 0.2341 & 0.4054 \\
\hline 130 & 38.422 & 0.2343 & 0.4058 & 38.455 & 0.2341 & 0.4055 \\
\hline 160 & 38.405 & 0.2344 & 0.4060 & 38.446 & 0.2341 & 0.4055 \\
\hline 200 & 38.378 & 0.2345 & 0.4062 & 38.445 & 0.2341 & 0.4056 \\
\hline
\end{tabular}

With regard to the pure aluminum films, the computed lattice parameter values of the samples deposited on the glass slides were larger than those for aluminum powder sample. Conversely, the measured lattice constants were smaller in the specimens deposited on silicon wafers (Table 4). Hence, the glass slide films underwent a structure expansion, while the films that were deposited on silicon wafers shrank. This finding is confirmed by the $2 \theta$ angle values (Table 4), which indicates residual tensile or compressive stresses that developed upon deposition of the film. [7,11,12]. Therefore, the trend observed may signal that the strained crystals of these films led to the weak intensity of the (111) peak in Figure 4 [37]. On the other hand, the $a$ and $2 \theta$ values remained relatively constant for all of the sputtering power levels studied (Table 4). These data suggest that the power levels studied did not generate added effects onto the pure aluminum films' structure for the sputtering parameters investigated.

The lattice parameters of the films made of Al-4B target displayed a different trend with respect to the pure aluminum films (Table 4). Some remarkable structural changes came about regarding the sputtering power. Such a difference was evident in the different $2 \theta$ positions and, consequently, the respective lattice constant values (Table 4 ). In the material deposited on the glass slide at $100 \mathrm{~W}$, the $a$ value was lower than $0.4052 \mathrm{~nm}$ of the aluminum powder sample, i.e., the residual compression stress prevailed. Conversely, under other sputtering power levels, the tensile stresses dominated, leading to larger lattice parameters. Even though, for the said deposition power levels, the film material's structure exhibited strain, it showed greater crystallinity when compared to its aluminum counterpart (Figure 4a). This effect on crystallinity may be due to the highly energetic sputtered atoms, which reduced the crystal defect density, even in low power sputtering $[12,28,33,37,40]$. On the silicon wafer, the film's residual stresses caused shrinkage with smaller $a$ values, as compared with the pure aluminum powder sample. As in the 
glass substrate, the crystallinity of the material was more significant than the aluminum film that was deposited under similar conditions onto the silicon substrate (Figure $4 \mathrm{~b}$ ). Additionally, regarding these samples, one can observe that raising sputtering power led to a lattice parameter close to the one in the pure aluminum powder, i.e., $0.4052 \mathrm{~nm}$. In effect, at $200 \mathrm{~W}$, the lattice parameter was $0.4051 \mathrm{~nm}$ (Table 4). Hence, this sample showed an apparently lower crystalline strain because of residual stresses. Furthermore, this phenomenon was not observed at lower sputtering power.

The XRD evaluation outcomes revealed that the Al-4B target material, under the sputtering parameters used in this study, produced a film with a better crystallinity when compared with the films prepared with the pure $\mathrm{Al}$ target (in particular, in the specimen deposited at $200 \mathrm{~W}$ on the silicon wafer). The material presented a marked texture, i.e., (111) plane, with a less strained lattice $(a=0.4051 \mathrm{~nm})$. Consequently, the grains may bear smaller defect density $[7,11]$. These features may have restricted the grains coalescence, preventing their growth and the hillocks development as the film thickened. Furthermore, one must remember that the $\mathrm{AlB}_{2}$-reinforced target may have also influenced the structures of the films. Although the diffractograms did not reveal the presence of those particles, the literature has confirmed the effect of alloys or composite on the structure of the films material $[7,11,13,33,40,41]$. Besides, the resulting films that were prepared with the composite target also displayed better mechanical behavior (i.e., higher hardness and elastic modulus). [11,13,42]. A prior research unveiled that the Al-4B target led to high hardness sputtered films bearing high elastic modulus and adhesion strength, when compared to aluminum films that were deposited under the same RF sputtering power condition $(200 \mathrm{~W})$ on a silicon wafer [19]. Therefore, the morphological and structural improvements that were found in $\mathrm{Al}-4 \mathrm{~B}$ thin films, in line with mechanical behavior reported above, make the methodology a potentially engaging alternative in aluminum films manufacturing.

\section{Conclusions}

The present work adds to a growing corpus of research on aluminum-based films deposited via sputtering magnetron. By characterizing the films through atomic force microscopy and X-ray diffraction, we tested the potential influence of amorphous and crystalline substrates, i.e., glass slides and silicon wafers.

First, the said glass and silicon substrates did not appear to influence the surface roughness of the aluminum film material. However, atomic force microscopy evinced how the films' roughness was affected by the film thickness and the sputtering power, as grains coalesced and hillocks formed.

The films that were deposited using the aluminum-boron composite target presented smaller grains and less roughness with hillock suppression when the highest sputtering power, i.e., $200 \mathrm{~W}$, was used.

X-ray diffraction revealed that the $\mathrm{Al}-4 \mathrm{~B}$ composite target rendered films bearing better crystallinity for the sputtering parameters that were used in this study than the films prepared with pure Al targets. Al-4B samples had a film growth with preferred orientation along the (111) crystallographic plane. Additionally, the film material presented less strain as the sputtering power increased.

The measured lattice parameters in the films revealed the influence of the target material, the substrate, and the sputtering power. Pure aluminum films presented an almost constant lattice parameter on the different substrates for the different RF power levels used. Conversely, the Al-4B films had different lattice parameters as the sputtering power increased. One can conclude that this material possessed a less strained crystal structure when the film was sputtered at the highest RF power of the silicon wafers. Future investigations are necessary for validating the conclusions on texture drawn from this study. 
Author Contributions: Conceptualization, O.M.S. and U.B.-V.; methodology, U.B.-V.; validation, U.B.-V.; formal analysis, U.B.-V.; investigation, U.B.-V.; resources, O.M.S.; data curation, U.B.-V.; writing-original draft preparation, U.B.-V.; writing-review and editing, U.B.-V. and O.M.S.; visualization, U.B.-V.; supervision, U.B.-V.; project administration, O.M.S.; funding acquisition, O.M.S. All authors have read and agreed to the published version of the manuscript.

Funding: This work was supported by the United States' National Science Foundation under grants Nº619349 and 0922994 (MRI Program), and 0833112 and 1345156 (CREST Program).

Institutional Review Board Statement: Not applicable.

Informed Consent Statement: Not applicable.

Data Availability Statement: The data presented in this study are available on request from the corresponding author. The data are not publicly available due to a proper institutional repository policy.

Acknowledgments: The authors would like to thank the departments of Civil Engineering \& Surveying and Engineering Science \& Materials of the University of Puerto Rico-Mayagüez, which partially supported this research undertaking. Finally, the authors would like to express their gratitude to professors Arturo Hernández and Agnes Padovani of the University of Puerto Rico-Mayagüez for providing access to their instrumentation.

Conflicts of Interest: The authors declare no conflict of interest. The funders had no role in the design of the study; in the collection, analyses, or interpretation of data; in the writing of the manuscript, or in the decision to publish the results.

\section{Appendix A}

Figure A1 exemplifies how the grain boundaries were outlined in the pure aluminum (Figure A1a) and Al-4B film (Figure A1b) deposited at $100 \mathrm{~W}$. Subsequently, the diameter was estimated using the measured area of each grain by the SPIP ${ }^{\mathrm{TM}}$ software. This procedure was carried out for the films that were sputtered using other sputtering powers (i.e., $130 \mathrm{~W}, 160 \mathrm{~W}$, and $200 \mathrm{~W})$.
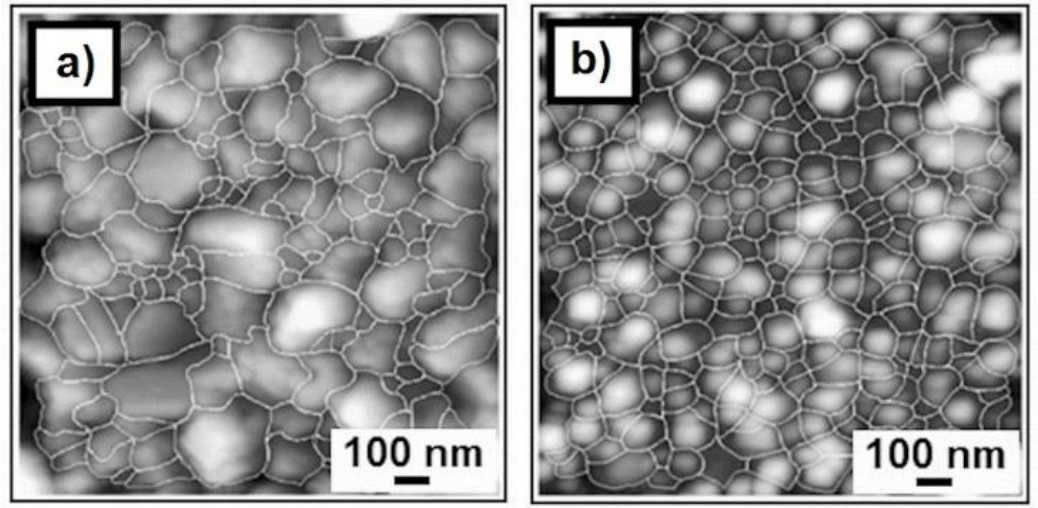

Figure A1. Grain boundary outline: (a) aluminum film and (b) Al-4B film. The AFM images correspond to films sputtered at $100 \mathrm{~W}$.

\section{References}

1. Khachatryana, H.; Leeb, S.-N.; Kimc, K.-B.; Kimd, H.-K.; Kim, M. Al thin film: The effect of substrate type on Al film formation and morphology. J. Phys. Chem. Solids 2018, 122, 109-117. [CrossRef]

2. Ottone, C.; Laurenti, M.; Bejtka, K.; Sanginario, A.; Cauda, V. The Effects of the Film Thickness and Roughness in the Anodization Process of Very Thin Aluminum Films. J. Mater. Sci. Nanotechnol. 2014, 1, 1-9. [CrossRef]

3. Hwang, S.; Lee, J.; Jeong, C.; Joo, Y. Effect of film thickness and annealing temperature on hillock distributions in pure Al films. Scr. Mater. 2007, 56, 17-20. [CrossRef]

4. Quintana, P.; Oliva, A.I.; Ceh, O.; Corona, J.E. Thickness effects on aluminum thin films. Superf. Vacío. 1999, 9, 280-282. Available online: https:/ / www.fis.cinvestav.mx/ \{\}smcsyv/supyvac/9/sv928099.pdf (accessed on 31 March 2021). 
5. Kang, T.J.; Kim, J.-G.; Lee, H.-Y.; Lee, J.-S.; Lee, J.-H.; Hahn, J.-H.; Kim, Y.H. Modification of Optical and Mechanical Surface Properties of Sputter-Deposited Aluminum Thin Films through Ion Implantation. Int. J. Precis. Eng. Man. 2014, 15, 889-894. [CrossRef]

6. Kylner, C.; Mattsson, L. Enhanced optical performance of aluminum films by copper inclusion. Thin Solid Film 1999, 348, $222-226$. [CrossRef]

7. Barron, L.W.; Neidrich, J.; Kurinec, S.K. Optical, electrical, and structural properties of sputtered aluminum alloy thin films with copper, titanium and chromium additions. Thin Solid Films 2007, 515, 3363-3372. [CrossRef]

8. Basaran, C.; Lin, M. Damage mechanics of electromigration induced failure. Mech. Mater. 2008, 40, 66-79. [CrossRef]

9. Onoda, H.; Narita, T.; Touchi, K.; Hashimoto, K. Effects of insulator surface roughness on Al-alloy film properties and electromigration performance in Al-alloy/Ti insulator layered interconnects. J. Vac. Sci. Technol. B 1996, 14, 2645-2655. [CrossRef]

10. Black, J.R. Electromigration failure modes in aluminum metallization for semiconductor devices. Proc. IEEE 1969, 57, 1587-1594. [CrossRef]

11. Ramos, G.; Suárez, O.M. Characterization of sputtered Al-B-Si thin films produced with composite targets for device applications. Sci. Eng. Compos. Mater. 2012, 19, 93-99. [CrossRef]

12. Onishi, T.; Iwamura, E.; Takagi, K. Effects of $\mathrm{Nd}$ content in $\mathrm{Al}$ thin films on hillock formation. J. Vac. Sci. Technol. A 1997, 15, 2339-2348. [CrossRef]

13. Wu, Z.; Bai, Y.; Qu, W.; Wu, A.; Zhang, D.; Zhao, J.; Jiang, X. Al-Mg-B thin films prepared by magnetron sputtering. Vacuum 2010, 85, 541-545. [CrossRef]

14. Draissia, M.; Boudemagh, H.; Debili, M.Y. Structure and Hardness of the Sputtered Al-Cu Thin Films System. Phys. Scr. 2004, 69, 348-350. [CrossRef]

15. Ishiguro, T.; Miyamura, K. Controllability of Mesoscopic Surface Roughness of Sputtered Al and Al-N Films. Mater. Trans. 2005, 46, 3037-3043. [CrossRef]

16. Melgarejo, Z.H.; Suárez, O.M.; Sridharan, K. Microstructure and properties of functionally graded Al-Mg-B composites fabricated by centrifugal casting. Compos. Part A Appl. Sci. Manuf. 2008, 39, 1150-1158. [CrossRef]

17. Adelakin, T.K.; Suárez, O.M. Study of Boride-Reinforced Aluminum Matrix Composites Produced via Centrifugal Casting. Mater. Manuf. Process 2011, 26, 338-345. [CrossRef]

18. Barajas-Valdes, U. Study of Light Weight, High Strength, Multifunctional Composite Material: Aluminum Reinforced with $\mathrm{AlB}_{2}$ Particles. Ph.D. Dissertation, Departmente of Civil Engineering, University of Puerto Rico, Mayaguez, Puerto Rico, 2017. Available online: https:/ / scholar.uprm.edu/handle/20.500.11801/910 (accessed on 31 March 2021).

19. Barajas-Valdes, U.; Suárez, O.M. Nanomechanical properties of thin films manufactured via magnetron sputtering from pure aluminum and aluminum-boron targets. Thin Solid Films 2020, 693, 137670-137679. [CrossRef]

20. Bordo, K.; Rubahn, H. Effect of Deposition Rate on Structure and Surface Morphology of Thin Evaporated Al Films on Dielectrics and Semiconductors. Mater. Sci. Medzg. 2012, 18, 313-317. [CrossRef]

21. Jang, K.-H.; Hwang, S.-J.; Joo, Y.-C. Effect of capping layer on hillock formation in thin Al films. Met. Mater. Int. 2008, 14, 147-150. [CrossRef]

22. Barron, L.W. High-Reflectance, Sputter-Deposited Aluminum Alloy Thin Films for Micro-Electro-Mechanical Systems. Master's Thesis, Department of Materials Science and Engineering, Rochester Institute of Technology, Rochester, NY, USA, 2005. Available online: https:/ / scholarworks.rit.edu/theses/5760/ (accessed on 31 March 2021).

23. Kim, D.; Heiland, B.; Nix, W.D.; Arzt, E.; Deal, M.D.; Plummer, J.D. Microstructure of thermal hillocks on blanket Al thin films. Thin Solid Films 2000, 371, 278-282. [CrossRef]

24. Martin, B.C.; Tracy, C.J.; Mayer, J.W.; Hendrickson, L.E. A comparative study of hillock formation in aluminum films. Thin Solid Films 1995, 271, 64-68. [CrossRef]

25. Raić, K.T. An explanation of hillock growth in thin Al films. Surf. Eng. 2016, 32, 1-6. [CrossRef]

26. Smith, D. Thin-Film Deposition. Principles and Practice; McGraw-Hill: New York, NY, USA, 1995; pp. $178-301$.

27. Ohring, M. The Materials Science of Thin Films, 2nd ed.; Academic Press: San Diego, CA, USA, 2002; pp. $403-449$.

28. Aceto, S.; Chang, C.Y.; Vook, R.W. Hillock growth on aluminum and aluminum alloy films. Thin Solid Films 1992, 219 , 80-86. [CrossRef]

29. Aurongzeb, D.; Washington, E.; Basavaraj, M.; Berg, J.M.; Temkin, H.; Holtz, M. Nanoscale surface roughening in ultrathin aluminum films. Appl. Phys. 2006, 100, 11-14. [CrossRef]

30. Montgomery, D.C.; Runger, G.C. Applied Statistics and Probability for Engineers, 3rd ed.; John Wiley \& Sons: New York, NY, USA, 2003; pp. 207-219.

31. Paul, A.; Wingbermu, J. Surface morphology for ion-beam sputtered Al layer with varying sputtering conditions. Appl. Surf. Sci. 2006, 252, 8151-8155. [CrossRef]

32. Le, M.-T.; Sohn, Y.-U.; Lim, J.-W.; Choi, G.-S. Effect of Sputtering Power on the Nucleation and Growth of Cu Films Deposited by Magnetron Sputtering. Mater. Trans. 2010, 51, 116-120. [CrossRef]

33. Ramos-Rivera, G. Fabrication, Characterization and Testing of Functionally Graded Aluminum-based Targets for Sputtering Deposition of Hybrid Composites. Master's Thesis, Department of Mechanical Engineering, University of Puerto Rico, Mayagüez, Puerto Rico, 2011. Available online: https:/ / scholar.uprm.edu/handle/20.500.11801/429 (accessed on 31 March 2021). 
34. Venables, J.; Spiller, G.; Hanbucken, M. Nucleation and growth of thin films. Rep. Prog. Physic. 1984, 47, 399-459. Available online: https:/ / iopscience.iop.org/article/10.1088/0034-4885/47/4/002 (accessed on 31 March 2021). [CrossRef]

35. Reichelt, K. Nucleation and Growth of Thin Films. Vacuum 1988, 38, 1083-1099. [CrossRef]

36. Franssila, S. Thin-film Growth and Structure. In Introduction to Microfabrication, 1st ed.; Franssila, S., Ed.; John Wiley \& Sons: England, UK, 2004; pp. 73-90.

37. Jeong, S.H.; Kho, S.; Jung, D.; Lee, S.B.; Boo, J. Deposition of aluminum-doped zinc oxide films by RF magnetron sputtering and study of their surface characteristics. Surf. Coat. Technol. 2003, 175, 187-192. [CrossRef]

38. Thompson, C.V.; Carel, R. Texture development in polycrystalline thin films. Mater. Sci. Eng. B 1995, 32, 211-219. [CrossRef]

39. Simon, A.H. Sputter Processing. In Handbook of Thin Film Deposition. Tech. Process. Technol, 3rd ed.; Seshan, K., Ed.; Elsevier Inc.: Oxford, UK, 2012; pp. 55-73.

40. Chaoumead, A.; Sung, Y.W.; Kwak, D. The Effects of RF Sputtering Power and Gas Pressure on Structural and Electrical Properties of ITiO Thin Film. Adv. Condens. Matte Phys. 2012, 2012, 1-7. [CrossRef]

41. Cullity, B.D.; Stock, S.R. Elements of X-ray Diffraction, 3rd ed.; Pearson New International: England, UK, 2014 ; pp. $237-239$.

42. Chen, Y.; Bakshi, S.R.; Agarwal, A. Correlation between nanoindentation and nanoscratch properties of carbon nanotube reinforced aluminum composite coatings. Surf. Coat. Technol. 2010, 204, 2709-2715. [CrossRef] 